\title{
Quality-related events reported by community pharmacies in Nova Scotia over a 7-year period: a descriptive analysis
}

\author{
Adrian Boucher BSc PharmD, Certina Ho BScPhm PhD, Neil MacKinnon MSc(Pharm) PhD, \\ Todd A. Boyle PhD, Andrea Bishop MHSA PhD, Paola Gonzalez MASc PhD, Christopher Hartt PhD, \\ James R. Barker MA PhD
}

\section{Abstract}

Background: Quality-related events are defined as medication errors that reach the patient (e.g., incorrect drug, dose and quantity), in addition to medication errors that are intercepted before dispensing (i.e., near misses). The aim of this study is to quantify and characterize such events as reported by community pharmacies in a Canadian province.

Methods: A retrospective analysis was conducted on quality-related events reported to the Community Pharmacy Incident Reporting system from 301 community pharmacies in Nova Scotia between Oct. 1, 2010, and June 30, 2017. We performed a descriptive analysis on these events with respect to the discoverer, patient outcome, medication system stages and type.

Results: We identified 131031 events reported by community pharmacies in Nova Scotia over the study period, 98097 of which were quality-related events. Overall, $82.0 \%(n=80488)$ quality-related events did not reach the patient, and $0.95 \%(n=928)$ were associated with patient harm. Incorrect dose or frequency, incorrect quantity and incorrect drug were the most common types of quality-related events reported. Most of the quality-related events occurred at order entry, followed by preparation and dispensing, and prescribing.

Interpretation: Quality-related events reported by community pharmacies differ from those reported in institutional settings with respect to patient outcome, medication system stages and type. This analysis provides valuable information to guide quality improvement initiatives to strengthen medication safety in community pharmacies.

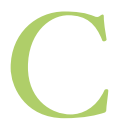
ommunity pharmacies in Canada dispense more than 600 million prescriptions each year; however, little is known about the quality-related events associated with this process. ${ }^{1-4}$ Quality-related events are defined as medication errors that reach the patient, such as incorrect drug, dose or quantity, in addition to medication errors that are intercepted before a drug is dispensed (i.e., near misses). ${ }^{2}$ These events occur when vulnerable medication-use systems or human factors affect prescribing, transcribing, dispensing, administration, and monitoring practices. ${ }^{5}$ When an event reaches a patient and causes harm, it is defined as an adverse drug event. ${ }^{6}$ Adverse drug events are estimated to be responsible for $12 \%$ of emergency department visits and $24 \%$ of all adverse events that occur in hospitals in Canada. ${ }^{7,8}$

In an effort to address factors that lead to quality-related events, health care organizations and governments have developed and implemented reporting systems. Aside from providing data for large-scale aggregate analysis, reporting systems enable health care stakeholders to better understand the contributing factors that may have led to quality-related events, and have been associated with improvements in patient safety culture and better organizational learning. ${ }^{9}$ The implementation of reporting systems in community pharmacies in Canada has been limited, but previous research involving analyses of quality-related events from community pharmacies in Europe showed differences from institutional settings with respect to patient outcome, stage of medication use and type of quality-related event. ${ }^{10,11}$ The aim of our study was to characterize quality-related events reported to an independent third-party national medication safety organization by community pharmacies in a Canadian province.

\section{Competing interests: None declared.}

This article has been peer reviewed.

Correspondence to: Certina Ho, certina.ho@utoronto.ca

CMAJ Open 2018. DOI:10.9778/cmajo.20180090 


\section{Methods}

The Nova Scotia College of Pharmacists Standards of Practice for Continuous Quality Assurance require community pharmacies to anonymously report all quality-related events to a national incident data repository at the Institute for Safe Medication Practices Canada through the Community Pharmacy Incident Reporting system. ${ }^{12}$ The Community Pharmacy Incident Reporting system was developed and validated with community pharmacists in Ontario and Nova Scotia. ${ }^{13}$ The provincial pharmacy regulatory authority regularly audits and ensures pharmacies' adherence to these standards.

\section{Study cohort}

All community pharmacies in Nova Scotia were included in the study.

\section{Data sources}

The quality-related event reporting form was developed in collaboration with Nova Scotia and Ontario community pharmacy professionals; it consists of 7 mandatory fields: (1) date quality-related event occurred, (2) type of event, (3) who the event was discovered by, (4) medication system stages involved, (5) medication(s), (6) patient outcome associated with the event, and (7) a free-text description field (Box 1). All members of the pharmacy team (e.g., owner, manager, pharmacist, technician, assistant) can report a quality-related event through the online Community Pharmacy Incident Reporting system.

\section{Statistical analysis}

All 7 mandatory fields of reported quality-related events from Nova Scotia community pharmacies that occurred between Oct. 1, 2010, and June 30, 2017, were extracted from the Community Pharmacy Incident Reporting system (by A. Boucher and C. Ho). Single-item and cross-tabulation search statements were developed to further extract relevant data for analysis (by A. Boucher and C. Ho). Descriptive analyses were performed on events with respect to discoverer, patient outcome, medication system stages involved and type (by A. Boucher and C. Ho). All analyses were performed using IBM SPSS version 24.

\section{Ethics approval}

This study does not involve human subjects.

\section{Results}

A total of 301 community pharmacies (Table 1) in Nova Scotia reported 131031 events to the Community Pharmacy Incident Reporting system during the study period. Of these events, 98097 were reported as quality-related events and were included in our analysis. A mean of 14533 qualityrelated events were reported annually. The mean number of reported quality-related events for each pharmacy during the study period was 326 (standard deviation $[\mathrm{SD}] \pm 439$ ). We found a large variability between pharmacies, with between 1 and 2806 quality-related events reported per pharmacy during the study period. Furthermore, $10 \%(n=30)$ of the pharmacies accounted for $42.7 \%(n=41926)$ of all reported qualityrelated events.

\section{Community pharmacies in Nova Scotia}

Most $(55.2 \% ; n=166)$ of the community pharmacies in Nova Scotia are chain pharmacies, and $48.2 \%(n=145)$ are located in a geographic region with a population of between 5000 and 49999 (Table 1).

\section{Discoverer}

Pharmacists discovered 75.2\% ( $n=73739)$ of quality-related events. Pharmacy technicians or assistants and patients discovered $10.3 \%(n=10094)$ and $9.9 \%(n=9728)$, respectively. The remaining $4.6 \%(n=4536)$ were discovered primarily by other health care practitioners (Appendix 1, available at www. cmajopen.ca/content/6/4/E651/suppl/DC1).

\section{Patient outcome}

Analysis of outcomes showed that $82.0 \%(n=80488)$ of reported quality-related events did not reach the patient (i.e., near misses), and $0.95 \%(n=928)$ were reported as harm events (Table 2).

\section{Medication system stage}

Of all analyzed quality-related events, $17.5 \%(n=17135)$ were reported as occurring in multiple medication system stages. The medication system stage most frequently associated with quality-related events was prescription order entry $(58.7 \% ; n=69856)$, followed by prescription preparation and dispensing $(29.3 \% ; n=34859)$ and prescribing $(9.0 \% ; n=$ 10658 ) (Table 3). Among harm events, there was a more even distribution across the medication system stages, with prescription preparation and dispensing $(38.1 \% ; n=571)$ accounting for the largest proportion, followed by order entry $(27.4 \% ; n=411)$ and administration $(15.2 \% ; n=228)$. Administration and monitoring or follow-up were associated with the highest potential for patient harm.

\section{Type of quality-related event}

The most frequently reported types of quality-related event were incorrect dose or frequency $(25.6 \% ; n=25089)$, followed by incorrect quantity $(20.0 \% ; n=19619)$ and incorrect drug $(14.2 \% ; n=13951)$ (Table 4). For harm events, the highest number of quality-related events was associated with incorrect dose or frequency $(27.4 \% ; n=254)$, followed by incorrect strength or concentration $(20.2 \% ; n=187)$ and incorrect drug $(19.9 \% ; n=185)$. Adverse drug reactions were associated with the highest potential for patient harm.

\section{Interpretation}

We identified 98097 quality-related events reported during the study period. Despite variability in reporting between pharmacies, $100 \%$ of community pharmacies in Nova Scotia $(n=$ 301) reported at least 1 such event during the study period, 
Box 1 (part 1 of 2): Mandatory fields of the Community Pharmacy Incident Reporting system

1. Date quality-related event occurred

2. Type of quality-related event*

- Incorrect patient

- Incorrect prescriber

- Incorrect drug

- Incorrect dose/frequency

- Incorrect strength/concentration

- Incorrect dosage form/formulation

- Incorrect route of administration

- Incorrect duration of treatment

- Incorrect quantity

- Incorrect storage

- Omitted medication/dose

- Incorrect third-party billing

- Drug therapy problem

- Contraindication

- Adverse drug reaction

- Documented allergy

- Drug-drug interaction

- Drug-food interaction

- Drug-disease interaction

3. Quality-related event discovered by (i.e., Discoverer)*

- Pharmacist

- Pharmacy technician/assistant

- Pharmacy student

- Patient

- Patient's family member/relative

- Patient's caregiver/home aid/assistant

- Patient's friend/visitor

- Community Care Access Centre home care coordinator

- Physician

- Medical student

- Paramedic

- Nurse

- Nursing student

- Social worker

- Dentist

- Midwife

- Chiropodist/podiatrist

- Respiratory therapist

- Dietician

- Physiotherapist

- Occupational therapist

- Veterinarian

- Other

4. Medication system stage involved $\dagger$

- Prescribing

- Prescription order entry

- Prescription preparation/dispensing
Box 1 (part 2 of 2): Mandatory fields of the Community Pharmacy Incident Reporting system

4. Medication system stage involved (continued) $\dagger$

- Administration

- Monitoring/follow-up

- Not applicable

5. Medicationsł

6. Degree of harm (i.e., patient outcome)*

- No error (medication not dispensed/near miss/medication discrepancy) - Circumstances or events that have the capacity to cause harm

- No harm (medication dispensed) - No symptoms detected; no treatment required

- Mild harm - Symptoms were mild, temporary and short-term; no treatment or minor treatment was required

- Moderate harm - Symptoms required additional treatment or an operation; the incident kept the patient in hospital longer than expected; or caused permanent harm or loss of function

- Severe harm - Symptoms required major treatment to save the patient's life; the incident shortened life expectancy; or caused major permanent or long-term harm

- Death - There is reason to believe that the incident caused the patient's death or hastened the patient's death

7. Quality-related event description

${ }^{*}$ The reporter may only select 1 option from this field.

†The reporter may select more than 1 option from this field.

fReporters have the option to report an event that is not medication-related by unchecking "Is this medication related" next to the "Medications" field. The "Medications" field will auto-populate if a drug identification number (DIN) is entered. A DIN is an 8-digit unique identifier located on the label of prescription and over-the-counter drugs that have been approved for sale in Canada. Reporters may also select the medication from a drop-down menu when the reporter begins typing the medication name, or they may choose to manually enter a free-form medication name.

Table 1: Pharmacy characteristics

\begin{tabular}{|lc|}
\hline Characteristic & $\begin{array}{c}\text { No. (\%) of } \\
\text { pharmacies } \\
n=301\end{array}$ \\
\hline Type of pharmacy* & \\
\hline Chain & $166(55.1)$ \\
\hline Banner & $111(36.9)$ \\
\hline Independent & $24(8.0)$ \\
\hline Population served by the pharmacy \\
\hline$<1000$ & $31(10.3)$ \\
\hline $1000-4999$ & $70(23.3)$ \\
\hline $5000-49999$ & $145(48.2)$ \\
\hline $50000-99999$ & $16(5.3)$ \\
\hline$>100000$ & $39(13.0)$ \\
\hline
\end{tabular}

${ }^{*}$ Chain pharmacies are typically directed by a corporate office, with respect to its professional programs, marketing, ordering, etc. Banner pharmacies are independently owned pharmacies that are affiliated with a central office; they pay fees for the banner's benefit in centralized buying, marketing and professional programs. Independent pharmacies are not affiliated with any corporately run chains or banners. The owner of an independent pharmacy has complete control over the business (e.g., ordering and marketing strategies). 
Table 2: Quality-related events reported by patient outcome

\begin{tabular}{|lccc|}
\hline $\begin{array}{l}\text { Event } \\
\text { reached } \\
\text { patient }\end{array}$ & Patient outcome & No. (\%) & $\begin{array}{c}\text { Harm } \\
\text { QRE }\end{array}$ \\
\hline No & $\begin{array}{c}\text { No error } \\
\text { (i.e., near miss) }\end{array}$ & $80488(82.0)$ & No \\
\hline Yes & No harm & $16681(17.0)$ & No \\
\hline Yes & Mild harm & $839(0.86)$ & Yes \\
\hline Yes & Moderate harm & $80(0.1)$ & Yes \\
\hline Yes & Severe harm & $7(0.00)$ & Yes \\
\hline Yes & Death & $2(0.00)$ & Yes \\
\hline Total & & $98097(100)$ & \\
\hline Note: QRE $=$ quality-related event. & & \\
\hline
\end{tabular}

Table 3: Total number of QREs, number of harm QREs and proportion of harm QREs for each medication system stage

\begin{tabular}{|c|c|c|c|}
\hline \multirow[b]{2}{*}{ Stage } & \multicolumn{2}{|c|}{ No. (\%) } & \multirow{2}{*}{$\begin{array}{c}\% \text { Harm } \\
\text { QREs* }\end{array}$} \\
\hline & QREs & Harm QREs* & \\
\hline Prescribing & $10658(9.0)$ & $159(10.6)$ & 1.5 \\
\hline $\begin{array}{l}\text { Prescription } \\
\text { order entry }\end{array}$ & $69856(58.7)$ & $411(27.4)$ & 0.6 \\
\hline $\begin{array}{l}\text { Prescription } \\
\text { preparation/ } \\
\text { dispensing }\end{array}$ & 34859 (29.3) & $571(38.1)$ & 1.6 \\
\hline Administration & 2167 (1.8) & 228 (15.2) & 10.5 \\
\hline $\begin{array}{l}\text { Monitoring/ } \\
\text { follow-up }\end{array}$ & $704(0.6)$ & $90(6.0)$ & 12.8 \\
\hline Not applicable & $743(0.6)$ & $39(2.6)$ & 5.2 \\
\hline Total & $118987 \dagger(100)$ & $1498 \dagger(100)$ & - \\
\hline \multicolumn{4}{|c|}{$\begin{array}{l}\text { Note:QRE = quality related event. } \\
\text { *Harm QREs are associated with a patient outcome of mild harm, moderate } \\
\text { harm, severe harm or death (Table 2). } \\
\text { †The reporter can select multiple options for "Medication System Stages } \\
\text { Involved" field; hence the total number of QREs and the number of QREs with } \\
\text { harm are greater than those shown in Table } 2 \text {. }\end{array}$} \\
\hline
\end{tabular}

suggesting universal compliance with the reporting program. Most of the events were discovered by a pharmacist and did not reach the patient. Quality-related events most frequently occurred in the order entry stage and were most commonly categorized as incorrect dose or frequency, or incorrect quantity.

Most of the events reported were caught by pharmacy staff and did not reach the patient. This result is in contrast to previous analyses of reported events from community pharmacies and hospitals where, in general, less than $60 \%$ of qualityrelated events did not reach the patient. ${ }^{10}$ This discrepancy may be due to several factors. First, in addition to anonymous reporting, the Nova Scotia Continuous Quality Assurance program also requires community pharmacies to perform an annual medication safety self-assessment and conduct quarterly staff meetings to implement and monitor ongoing quality improvement initiatives. ${ }^{12}$ These additional quality improvement components help facilitate quality-related event reporting by addressing several common barriers to incident reporting, including lack of feedback on action taken as a result of reporting, insufficient justification for reporting a "near miss" and the belief that reporting is unlikely to lead to system changes. ${ }^{14,15}$ Second, adherence to all required components of the Standards of Practice for Continuous Quality Assurance are regularly audited and enforced by the provincial pharmacy regulatory authority. As a result, our data and analysis may provide a more representative view of quality-related events and associated outcomes that occur in community pharmacies.

The most common medication system stages involved in the reported quality-related events were prescription order entry and prescription preparation and dispensing. Previous studies in community pharmacies have found similar results, ${ }^{10,11}$ but studies in hospitals generally report a higher frequency of quality-related events related to prescribing and administration. ${ }^{16-19}$ In addition, we found that qualityrelated events that occurred during administration or monitoring and follow-up were more likely to result in patient harm, probably because there are fewer opportunities to catch quality-related events in later stages of the medicationuse process, and patients are more likely to identify and report events that cause harm. ${ }^{20}$ The most frequent types of reported quality-related events (e.g., incorrect dose or frequency, incorrect quantity, incorrect drug) were generally in agreement with results from previous studies conducted in community pharmacies and hospitals. ${ }^{11,16,17,21}$ However, other types of quality-related events were often reported in different proportions in hospital studies. ${ }^{16,17} \mathrm{We}$ found that adverse drug reactions may convey a higher risk of harm to patients compared with other types of quality-related events, which aligns with previous research that identified adverse drug reactions to be the most common cause for drugrelated emergency department visits. ${ }^{7}$

\section{Limitations}

We found significant variability in the reporting rates among community pharmacies. This finding is in line with results from previous research and may imply under-reporting of qualityrelated events to some extent. ${ }^{10,22}$ In addition, our findings represent quality-related events reported from a single reporting system in a single province. Because community pharmacies are largely governed by provincial pharmacy regulatory authorities, our results may not be generalizable to the rest of Canada. Nonetheless, our findings will provide important comparative data for other provincial pharmacy regulatory authorities in Canada, which are mandating quality-related event reporting in the coming years. ${ }^{23,24}$

\section{Conclusion}

We aimed to characterize quality-related events reported from community pharmacies in Nova Scotia. We found that these events differ from those reported in institutional settings 


\begin{tabular}{|c|c|c|c|}
\hline Type & No. $(\%)$ of QREs & $\begin{array}{c}\text { No. }(\%) \text { of } \\
\text { harm QREs* }\end{array}$ & $\begin{array}{c}\text { Proportion of } \\
\text { harm QREs*, } \\
\%\end{array}$ \\
\hline Incorrect dose or frequency & $25089(25.6)$ & $254(27.4)$ & 1.0 \\
\hline Incorrect quantity & $19619(20.0)$ & $19(2.0)$ & 0.1 \\
\hline Incorrect drug & $13951(14.2)$ & $185(19.9)$ & 1.3 \\
\hline Incorrect strength or concentration & $10508(10.7)$ & $187(20.2)$ & 1.8 \\
\hline Incorrect prescriber & $8454(8.6)$ & $0(0)$ & 0.0 \\
\hline Incorrect patient & $5685(5.8)$ & $32(3.4)$ & 0.6 \\
\hline Incorrect duration of treatment & $5048(5.1)$ & $18(1.9)$ & 0.4 \\
\hline $\begin{array}{l}\text { Incorrect dosage form or formulation (including } \\
\text { not splitting tablets as per patient's request) }\end{array}$ & $3281(3.3)$ & $32(3.4)$ & 1.0 \\
\hline Omitted medication or dose & $1919(2.0)$ & $58(6.23$ & 3.0 \\
\hline Incorrect route of administration & $1121(1.1)$ & $7(0.8)$ & 0.6 \\
\hline Incorrect storage & $857(0.9)$ & $3(0.3)$ & 0.4 \\
\hline Incorrect third-party billing & $803(0.8)$ & $1(0.1)$ & 0.1 \\
\hline $\begin{array}{l}\text { Drug therapy problem - drug-drug/OTC/ } \\
\text { natural health product interaction }\end{array}$ & $506(0.5)$ & $19(2.0)$ & 3.8 \\
\hline Drug therapy problem — documented allergy & $447(0.5)$ & $31(3.3)$ & 6.9 \\
\hline Drug therapy problem - contraindication & $356(0.4)$ & $12(1.3)$ & 3.4 \\
\hline Expired medication & $191(0.2)$ & $9(1.0)$ & 4.7 \\
\hline Drug therapy problem — adverse drug reaction & $188(0.2)$ & $56(6.0)$ & 29.8 \\
\hline $\begin{array}{l}\text { Drug therapy problem - drug-disease } \\
\text { interaction }\end{array}$ & $63(0.1)$ & $3(0.3)$ & 4.8 \\
\hline Drug therapy problem - drug-food interaction & $11(0.0)$ & $2(0.2)$ & 18.2 \\
\hline Total & $98097(100)$ & $928(100)$ & - \\
\hline
\end{tabular}

with respect to patient outcome, medication system stages and types of event. Although our findings provide an important first step in describing quality-related events in community pharmacies, they are unable to provide insight into the various factors that may contribute to these events. Future research should focus on the medications involved and qualitative analysis of the event description to better understand the potential contributing factors associated with quality-related events in community pharmacy practice. Combined with quantitative analysis, such research will provide a comprehensive view of key safety risks and trends, thus allowing for the development of recommendations to improve medication safety.

\section{References}

1. Paquette A. Special report: Top drugs of 2015. Pharmacy Practice Plus. Canadian Healthcare Network; 2016. Available: www.canadianhealthcarenetwork.ca/ pharmacists/magazines/pharmacy-practice-plus/julyaugust-2016/special-report-top -drugs-of-2015-36905 (accessed 2018 June 5). Login required to access content.
2. Boyle TA, Bishop AC, Duggan K, et al. Keeping the "continuous" in continuous quality improvement: Exploring perceived outcomes of CQI program use in community pharmacy. Res Social Adm Pharm 2014;10:45-57.

3. Boyle TA, Bishop A, Morrison B, et al. Pharmacist work stress and learning from quality related events. Res Social Adm Pharm 2016;12:772-83.

4. Boyle TA, Bishop AC, Overmars C, et al. Uptake of quality-related event standards of practice by community pharmacies. 7 Pharm Pract 2015;28:442-9.

5. Medication without harm - Global patient safety challenge on medication safety. Geneva: World Health Organization; 2017. License: CC BY-NC-SA 3.0 IGO. Available: http://apps.who.int/iris/bitstream/10665/255263/1/ WHO-HIS-SDS-2017.6-eng.pdf?ua=1\&ua=1 (accessed 2018 June 5).

6. Definition of terms. Toronto: Institute for Safe Medication Practices Canada (ISMP Canada). Available: www.ismp-canada.org/definitions.htm (accessed 2018 June 5 ).

7. Zed PJ, Abu-Laban RB, Balen RM, et al. Incidence, severity and preventability of medication-related visits to the emergency department: a prospective study. CMA7 2008;178:1563-9.

8. Baker GR, Norton PG, Flintoft V, et al. The Canadian Adverse Events Study: the incidence of adverse events among hospital patients in Canada. CMAf 2004;170:1678-86.

9. Hutchinson A, Young TA, Cooper KL, et al. Trends in healthcare incident reporting and relationship to safety and quality data in acute hospitals: results from the National Reporting and Learning System. Qual Saf Health Care 2009;18:5-10. 
10. Cheung KC, van den Bemt PM, Bouvy ML, et al. A nationwide medication incidents reporting system in The Netherlands. 7 Am Med Inform Assoc 2011; 18:799-804.

11. Knudsen P, Herborg H, Mortensen AR, et al. Preventing medication errors in community pharmacy: frequency and seriousness of medication errors. Qual Saf Health Care 2007;16:291-6.

12. Standards of practice: Continuous quality assurance programs in community pharmacies. Halifax: Nova Scotia College of Pharmacists; 2010. Available: www.nspharmacists.ca/wp-content/uploads/2018/01/SOP_ContinuousQualityAssuranceProgramsInCommunityPharmacies.pdf (accessed 2018 June 5).

13. Ho C, Hung P, Lee G, et al. Community pharmacy incident reporting: a new tool for community pharmacies in Canada. Healthc Q 2010;13:16-24.

14. Evans SM, Berry JG, Smith BJ, et al. Attitudes and barriers to incident reporting: a collaborative hospital study. Qual Saf Health Care 2006;15:39-43.

15. Boyle TA, Scobie AC, MacKinnon NJ, et al. Implications of process characteristics on quality-related event reporting in community pharmacy. Res Social Adm Pharm 2012;8:76-86.

16. Cousins DH, Gerrett D, Warner B. A review of medication incidents reported to the National Reporting and Learning System in England and Wales over 6 years (2005-2010). Br 7 Clin Pharmacol 2012;74:597-604.

17. Samsiah A, Othman N, Jamshed S, et al. Medication errors reported to the National Medication Error Reporting System in Malaysia: a 4-year retrospective review (2009 to 2012). Eur 7 Clin Pharmacol 2016;72:1515-24.

18. Tyynismaa L, Honkala A, Airaksinen M, et al. Identifying high-alert medications in a university hospital by applying data from the medication error reporting system. F Patient Saf 2017 June 1. [Epub ahead of print]. doi: 10.1097/ PTS.0000000000000388.

19. Miller MR, Clark JS, Lehmann CU. Computer based medication error reporting: insights and implications. Qual Saf Health Care 2006;15:208-13.

20. Reason J. Human error: models and management. BMF 2000;320:768-70.

21. Phipps DL, Tam WV, Ashcroft DM. Integrating data from the UK national reporting and learning system with work domain analysis to understand patient safety incidents in community pharmacy. 7 Patient Saf 2017;13:6-13.

22. Levinson DR. Hospital incident reporting systems do not capture most patient harm. Washington (DC): Office of the Inspector General; January 2012. Available: https://psnet.ahrq.gov/resources/resource/23842/hospital-incident -reporting-systems-do-not-capture-most-patient-harm (accessed 2018 June 5)

23. The regulatory bylaws of the Saskatchewan College of Pharmacy Professionals. Regina: Saskatchewan College of Pharmacy Professionals (SCPP); 2015 Oct. 16; updated 2018 Mar. 16. Available: https://scp.in1 touch.org/document/3584/ Bylaws_Regulatory_20170825.pdf (accessed 2018 June 5).
24. Ontario College of Pharmacists selects Pharmapod to implement medication error reporting system for Ontario pharmacies [news release]. Toronto: Ontario College of Pharmacists; 2017 Oct. 26. Available: www.ocpinfo.com/ library/news/pharmapod-cqa-announcement/ (accessed 2018 June 5).

Affiliations: Leslie Dan Faculty of Pharmacy (Boucher, Ho), University of Toronto; Institute for Safe Medication Practices Canada (Boucher, Ho), Toronto, Ont.; James L. Winkle College of Pharmacy (MacKinnon), University of Cincinnati, Cincinnati, OH; Gerald Schwartz School of Business (Boyle), St. Francis Xavier University, Antigonish, NS; IWK Health Centre (Bishop); Rowe School of Business (Gonzalez, Barker), and Department of Business and Social Science (Hartt), Dalhousie University, Halifax, NS

Contributors: Adrian Boucher and Certina Ho contributed substantially to the conception and design, acquisition of data, analysis and interpretation of data, drafted the article, and revised it critically for important intellectual content. Neil MacKinnon, Todd Boyle and Andrea Bishop contributed substantially to the conception and design, and the analysis and interpretation of data, and revised the manuscript critically for important intellectual content. Paola Gonzalez, Christopher Hartt and James Barker contributed substantially to the analysis and interpretation of data, and revised the manuscript critically for important intellectual content. All of the authors gave final approval of the version to be published and agreed to act as guarantors of the work.

Funding: This study was funded by The Kenneth C. Rowe Gift, Rowe School of Business, Dalhousie University, Halifax, NS.

Acknowledgements: The authors acknowledge the Institute for Safe Medication Practices Canada for providing access to the anonymously reported quality-related events by Nova Scotia community pharmacies that made this study possible; and the SafetyNET-Rx Participating Investigators who contributed to the review and editing of the manuscript.

Supplemental information: For reviewer comments and the original submission of this manuscript, please see www.cmajopen.ca/content/6/4/ E651/suppl/DC1. 